Brazilian Journal

of Chemical

Engineering

ISSN 0104-6632

Printed in Brazil

www.abeq.org.br/bjche

Vol. 36, No. 02, pp. 969 - 978, April - June, 2019

dx.doi.org/10.1590/0104-6632.20190362s20180395

\title{
STABILITY AND TOXICITY PROFILE OF SOLUTION ENHANCED DISPERSION BY SUPERCRITICAL FLUIDS (SEDS) FORMULATED Andrographis paniculata EXTRACT
}

\author{
S. Y. Lee ${ }^{1}$, L. Chuah Abdullah ${ }^{2}$, R. A. Rahman ${ }^{1,3}$, \\ F. Abas ${ }^{4}$ and G. H. Chong ${ }^{1,3^{*}}$ \\ ${ }^{1}$ University Putra Malaysia, Faculty of Food Science and Technology, Department of Food Technology, Selangor Darul Ehsan, Malaysia. \\ ORCID: 0000-0003-1542-3594; ORCID: 0000-0001-7358-0390; E-mail: gunhean@upm.edu.my - ORCID: 0000-0002-6521-1832 \\ ${ }^{2}$ University Putra Malaysia, Faculty of Engineering, Department of Chemical and Environmental Engineering, \\ Selangor Darul Ehsan, Malaysia. ORCID: 0000-0003-4785-9296 \\ ${ }^{3}$ University Putra Malaysia, Faculty of Food Science and Technology, Supercritical Fluid Centre, Selangor Darul Ehsan, Malaysia. \\ ${ }^{4}$ University Putra Malaysia, Faculty of Food Science and Technology, Department of Food Science, Selangor Darul Ehsan, Malaysia. \\ ORCID: 0000-0002-8110-9424
}

(Submitted: August 22, 2018 ; Revised: November 8, 2018 ; Accepted: December 11, 2018)

\begin{abstract}
The main objective was to evaluate the stability and toxicity of a Solution Enhanced Dispersion by Supercritical Fluids (SEDS) formulated A. paniculata extract that was intended for food applications. The best formulated SEDS A. paniculata extract with improved dissolution of andrographolide (data not shown) was obtained using $25 \mathrm{mg} / \mathrm{mL}$ A. paniculata extract (maceration in acetone) and $6 \mathrm{mg} / \mathrm{mL}$ Eudragit L100-55 with acetone as feed solvent at the following SEDS co-precipitation conditions: $150 \mathrm{bar}, 40{ }^{\circ} \mathrm{C}, 15 \mathrm{~L} / \mathrm{min} \mathrm{CO}_{\text {f }}$ flow rate $\left(1 \mathrm{bar}, 25^{\circ} \mathrm{C}\right), 0.5 \mathrm{~mL} / \mathrm{min}$ liquid feed flow. Sticky A. paniculata extract with $16 \% \mathrm{w} / \mathrm{w}$ andrographolide was transformed into SEDS co-precipitates concentrated with $20.4 \% \mathrm{w} / \mathrm{w}$ andrographolide. Only $20-30 \%$ of andrographolide was degraded after two-month storage under $5,30,45^{\circ} \mathrm{C}$ at $75 \%$ relative humidity (RH). About $30-60 \%$ of andrographolide was degraded after addition into drinking water, orange drink, soybean milk for a day. This would imply its unstable nature after being dispersed and wetted in liquid food. SEDS co-precipitate was found to be practically acetone-free $(<0.1 \mathrm{ppm})$ by Headspace Gas Chromatography-Mass Spectrometry (GC-MS). This showed the capability of the SEDS process in stripping off acetone. Higher cytotoxic potential of SEDS co-precipitates $\left(\mathrm{LC}_{50}=46.46 \mu \mathrm{g} / \mathrm{mL}\right)$ than extract $\left(\mathrm{LC}_{50}=150.45 \mu \mathrm{g} / \mathrm{mL}\right)$ was observed.

Keywords: Stability; Toxicity; SEDS; Andrographis paniculata; Co-precipitates.
\end{abstract}

\section{INTRODUCTION}

Herbs are processed into forms of essential oils, ointments, salves, and rubs for topical application or into forms of whole herbs, teas, syrups, capsules, and tablets for oral consumption (Wachtel-Galor and Benzie, 2011). However, liquid forms of herbal products are usually found to have lower chemical, physicochemical and microbiological stability that often hinder their applications. Therefore, formulation of liquid herbal product into solid counterparts has been developed to improve their quality and to ensure safe applications (Ameri and Maa, 2006; Bakowska-Barczak and Kolodziejczyk, 2011; Bhandari and Howes, 1999; Bott et al., 2010; Jiménez-Aguilar et al., 2011; Rocha et al., 2012; Yatsu et al., 2011). Transformation of those liquid herbal extracts into dry extracts has resulted in higher concentration of active compounds, ease of

\footnotetext{
* Corresponding author: Gun H. Chong - E-mail: gunhean@upm.edu.my
} 
standardization, ease of transportation, less storage space required, as well as ease of future translation into different solid pharmaceutical forms for the dry extract (Oliveira et al., 2010).

The common transformation methods used include spray drying, spouted bed drying as well as freeze drying (de Oliveira et al., 2012). While spray drying is the most common method used in herbal processing industries, supercritical fluid (SCFs)-based particulate technology has been found to be feasible for producing other herbal products such as powdered green tea extract, paprika extract, ginger and thyme extract (King, 2014). Application of SCFs is a greener technique that eliminates the most common drawbacks associated with the conventional methods such as thermal degradation, chemical degradation and high residual solvent content due to the larger diffusivities of SCFs than those of liquids, enabling high mass transfer rates during the transformation of liquid herbal extract into dry extract under moderate pressure-temperature conditions.

In spite of the capability of in minimizing undesirable changes during the transformation process, the stability of bioactive compounds in the final dry extract is equally important to preserve good quality of the dry extract. Studies related to the stability of andrographolide from different formulations such as those in powdered $A$. paniculata, aqueous $A$. paniculata extract, isolated andrographolide from $A$. paniculata extract, solid dispersion in polyvinylpyrrolidone (PVP-K30) as well as solid dispersion in silicon dioxide $\left(\mathrm{SiO}_{2}\right)$ have been conducted and reported (Ibrahim and Chong, 2008; Lomlim et al., 2003; Pholphana et al., 2004; Plubrukarn et al., 2006; Wongkittipong et al., 2004; Zhang et al., 2016). Thus far, first and secondorder kinetics of degradation of andrographolide have been reported (Lomlim et al., 2003; Plubrukarn et al., 2006; Wongkittipong et al., 2004). High storage temperature such as 45 to $70{ }^{\circ} \mathrm{C}$ and 86 to $97^{\circ} \mathrm{C}$ resulted in degradation of andrographolide and the degree of degradation increased with temperature (Lomlim et al., 2003; Plubrukarn et al., 2006; Wongkittipong et al., 2004), while lower storage temperatures such as 5 to 30 ${ }^{\circ} \mathrm{C}$ caused no significant reduction of andrographolide along the study period (Ibrahim and Chong, 2008).

Beside stability, toxicity of the formulated extract is undeniably another important factor to be considered for both formulators and consumers. The solvent residue in the final treated product is always the concern, especially if solvent is involved in the process. Throughout the studies reported on SCFstreated compounds, it was found that the residual amount of solvent, particularly Class III solvents such as dichloromethane (DCM), acetone, and dimethyl sulfoxide (DMSO) was much lower than the International Conference on Harmonization (ICH) requirements (5000 ppm) (Miao et al., 2018; Zhao et al., 2010). While solvent residue content of product could indirectly tell its toxicity potential, a general bioassay proposed by Meyer et al. (1982) could be used to identify the in vivo toxicity of co-precipitates towards newly hatch nauplii. In a brine shrimp study (Mamatha, 2014), crude $A$. paniculata extract was found to have a $\mathrm{LC}_{50}$ in the range of 100 to $300 \mu \mathrm{g} / \mathrm{mL}$.

In this study, stability and toxicity of a Solution Enhanced Dispersion by Supercritical Fluids (SEDS) formulated $A$. paniculata extract which was intended for food applications were evaluated. Degradation kinetics of andrographolide from SEDS co-precipitates was investigated under different storage conditions (5, 30 , and $45^{\circ} \mathrm{C}$ at $75 \%$ relative humidity $(\mathrm{RH})$ ) for a twomonth storage period. The half-life $\left(t_{1 / 2}\right)$ and shelf life $\left(t_{90 \%}\right)$ predicted were used to identify the most effective storage condition for the SEDS co-precipitates. On the other hand, the stability of andrographolide from SEDS co-precipitates after their respective addition into three different Ready-To-Drink (RTD) beverages of different $\mathrm{pH}$, namely drinking water, orange drink, and soybean milk was determined to evaluate their application stability for three days. The toxicity profile of the SEDS co-precipitates was elucidated through a solvent residue test by Headspace Gas Chromatography-Mass Spectrometry (GC-MS) analysis and brine shrimp bioassay.

\section{MATERIALS AND METHODS}

\section{Materials}

Fresh flowering $A$. paniculata were collected from a cultivated herb nursery named "Pusat Pembangunan Komoditi Sendayan" located in Negeri Sembilan, Malaysia. The aerial parts were authenticated by Dr. Shamsul Khamis, a botanist from the Biodiversity Unit of Institute of Bioscience, Universiti Putra Malaysia (UPM). A voucher specimen (Voucher No. SK 2767/15) was prepared and deposited in the herbarium. The collected $A$. paniculata were first cleaned with tap water, drained, then cut into 5-6 cm long pieces and dried under shade for three weeks. It was then milled with a 3 horsepower (hp) tea bag cutting mill (RT-CR30S, Rong Tsong Precision Technology Co., Taiwan) into coarse $A$. paniculata powder, followed by storage in a freezer until further use. High Performance Liquid Chromatography (HPLC) grade methanol with purity of 99.99\% was used in HPLC analysis and in brine shrimp bioassay as both control and solvent while acetone of Gas Chromatography (GC) Resolv grade with purity of 99.5\% was used in GC-MS analysis as standard (Fisher Scientfic, UK). Analytical grade acetone with purity of 99.98\% was used for other analyses (Fisher Scientific, UK). Andrographolide standard with a purity of 98\% was used (Sigma-Aldrich, USA). Three RTD 
beverages of different $\mathrm{pH}$ to simulate three different $\mathrm{pH}$ media such as SeaMaster Drinking Water ( $\mathrm{pH}$ 7.03) (RO Water Sdn. Bhd., Malaysia), MARIGOLD orange drink enriched with Vitamin $\mathrm{C}(\mathrm{pH}$ 3.89) (Malaysia Milk Sdn. Bhd., Malaysia), and Yeo's Soy Bean Milk Less Sugar (pH 6.66) (Yeo Hiap Seng (Malaysia) Bhd, Malaysia) were used. Brine shrimp eggs in sea salt premix ( $47 \mathrm{~g}$ of sea salt and $3 \mathrm{~g}$ of Artemia Cysts from the Great Salt Lake) (Ocean Nutrition, Belgium) and sodium chloride of ACS grade (Fisher Scientific, UK) were used for the brine shrimp bioassay. All chemicals were used as received.

\section{Extraction of $A$. paniculata}

Extraction of $A$. paniculata was conducted as described by Sule et al. (2011). Powdered A. paniculata $(1.5 \mathrm{~kg})$ was extracted by macerating in acetone $(6 \mathrm{~L})$ at room temperature for $24 \mathrm{~h}$, followed by filtration using filter paper (Whatman no. 1). The filtrate was concentrated under vacuum at $40{ }^{\circ} \mathrm{C}$. The extraction process was repeated twice. The dark blackish green A. paniculata extract obtained was stored in a freezer until further use.

\section{SEDS process for producing co-precipitates}

SEDS co-precipitation of $A$. paniculata extract with Eudragit L100-55 was conducted using a SEDS system that was designed and fabricated in-house as reported (Lee et al., 2018). A schematic diagram of the apparatus is shown in Figure 1.

It consisted of two high pressure pumps, one of them (PM-10000C, Delta, Taiwan Supercritical Technology, Taiwan) was used for liquid $\mathrm{CO}_{2}$ delivery into a preheated water bath that would later lead to the precipitation chamber, while another $(260 \mathrm{D}$, Teledyne Isco, USA) was used for liquid feed delivery. A cylindrical vessel of $1 \mathrm{~L}$ internal volume (internal diameter $=75 \mathrm{~mm}$ ) was used as the precipitation chamber. A stainless steel coaxial mixing nozzle (SETOJet 0405R, Kirinoikeuchi, Japan) that could produce a mean droplet diameter down to $50 \mu \mathrm{m}$ or less was used for spraying of both $\mathrm{CO}_{2}$ and liquid feed. The nozzle was infixed in the spiral lid of the precipitation chamber. The experiment was started by first cooling $\mathrm{CO}_{2}$ from a cylinder with the aid of a refrigerated circulated bath with temperature set at $4{ }^{\circ} \mathrm{C}$ to liquefy $\mathrm{CO}_{2}$ before being pumped to avoid cavitation. $\mathrm{CO}_{2}$ was then preheated to $40^{\circ} \mathrm{C}$ and pumped into the precipitation chamber through a nozzle. Pressure of the system was measured by a pressure gauge (EN837-1, WIKA, USA) and regulated by a back pressure regulator (26-1700, Tescom, US) located at the exit of the precipitation chamber. Temperature was set by a proportionalintegral-derivative (PID) controller connected with an electrically controlled heating jacket. The following parameters: $150 \mathrm{bar}, 40^{\circ} \mathrm{C}, 15 \mathrm{~L} / \mathrm{min}$ of $\mathrm{CO}_{2}$ flow rate

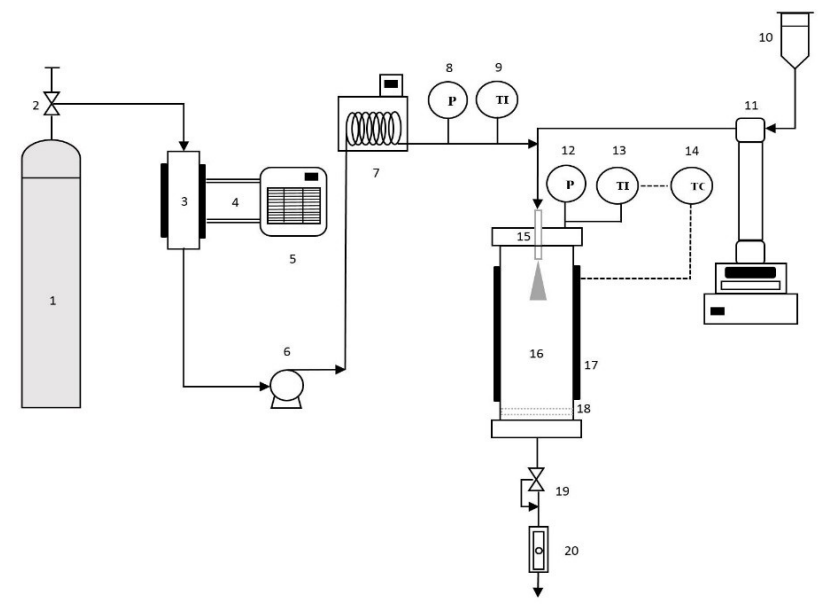

(Source: Reprinted from Chemical Engineering Research and Design, Vol. 138, Lee, S.Y., Abdullah, L.C., Abdul Rahman, R., Abas, F., Tan, W.K., Chong, G.H., Solution enhanced dispersion by supercritical fluids (SEDS): An approach in particle engineering to modify aqueous solubility of andrographolide from Andrographis paniculata extract, 176-189, Copyright 2018, with permission from Elsevier.)

Figure 1. Schematic diagram of the Solution Enhanced Dispersion by Supercritical Fluids (SEDS) apparatus. (1) $\mathrm{CO}_{2}$ cylinder; (2) $\mathrm{CO}_{2}$ cylinder outlet valve; (3) Low pressure heat exchanger; (4) Cooling lines for $\mathrm{CO}_{2}$; (5) Refrigerated circulating bath; (6) High pressure pump; (7) Water bath for preheating $\mathrm{CO}_{2} ;(8,12)$ Pressure gauge; $(9,13)$ Temperature indicator; (10) Feed solution; (11) Syringe pump; (14) Temperature controller; (15) Coaxial mixing nozzle; (16) Precipitation chamber; (17) Heating jacket; (18) Filter; (19) Back pressure regulator; (20) Rotameter.

( 1 bar, $25^{\circ} \mathrm{C}$ ), and $0.5 \mathrm{~mL} / \mathrm{min}$ of liquid feed flow rate were set constant throughout the experiment as they were the most appropriate conditions that resulted in successful co-precipitation of $A$. paniculata extract with Eudragit L100-55 with improved dissolution of andrographolide (data not shown). After the operating conditions were achieved and remained stable (chosen pressure, temperature, $\mathrm{CO}_{2}$ flow rate), the liquid feed was delivered by a syringe pump at constant flow rate $(0.5 \mathrm{~mL} / \mathrm{min})$ into the precipitation chamber. Acetone was used as feed solvent to dissolve both $A$. paniculata extract and Eudragit L100-55, followed by filtration using filter paper (Whatman no. 1) to form $25 \mathrm{mg} /$ $\mathrm{mL}$ of A. paniculata extract and $6 \mathrm{mg} / \mathrm{mL}$ of Eudragit L100-55 in the final liquid feed.

At the end of the liquid feed delivery, sc- $\mathrm{CO}_{2}$ was further delivered into the precipitation chamber for $45 \mathrm{~min}$ as a washing step for removal of any possible residual organic solvent within the chamber that would re-dissolve the formed particles upon depressurization. A filter was placed at bottom of precipitation chamber to collect the produced powder, while at the same time allowing $\mathrm{CO}_{2}$-solvent to pass through the chamber exit. At the exit of precipitation chamber, the $\mathrm{CO}_{2}$ flow rate was measured by a rotameter (LZT-08A10M-V, 
NBDC, China). At the end of the $\mathrm{CO}_{2}$ washing step, the $\mathrm{CO}_{2}$ flow was stopped, the precipitation chamber was slowly depressurized down to atmospheric pressure and the sample powder was collected for further analysis and characterization.

\section{Morphology of SEDS co-precipitates}

The morphology of the SEDS co-precipitates was analyzed with scanning electron microscopy (SEM) (JEOL JSM 6400, Japan). Prior to scanning, the sample was mounted on carbon tape and coated with a $450 \dot{A}$ thickness of gold under vacuum for 3 min using a sputter coater (SCD 005, BAL-TEC, Liechtenstein) to avoid charging under the electron beam during viewing.

\section{Crystallinity (XRD)}

Powder crystallinity of the SEDS co-precipitates was characterized with an X-ray diffractometer (PW3040/60 MPD X'Pert High Pro Panalytical, Philips, Netherlands) with $\mathrm{Cu} \mathrm{K} \alpha$ radiation with a $\mathrm{K}-\mathrm{A} 2 / \mathrm{K}-\mathrm{A} 1$ ratio of 0.5 , generated under a voltage of $40 \mathrm{kV}$ and a current of $40 \mathrm{~mA}$. Samples were scanned over the most informative range from $10^{\circ}$ to $80^{\circ}$ with a step size of $0.033^{\circ}$ and step time $19.6850 \mathrm{sec}$.

\section{Andrographolide content}

Andrographolide content of the SEDS coprecipitates was quantified by HPLC as described by Panossian et al. (2000). A LC system (1200 series, Agilent Technologies, USA) comprising of a micro vacuum degasser (G1322A, JP73069224), a quaternary pump (G1311A, DE62969377), an auto sampler (G1329A, DE64771769), DAD diode array detector (G1315D, DE64260468), and thermostatted column compartment (G1316A, DE90374060) was used. Chromatographic separation was carried out with a C18 column, 4.6 x $150 \mathrm{~mm}, 5 \mu \mathrm{m}$ (Zorbax Eclipse Plus, Agilent Technologies, USA). The mobile phase, composed of $60 \%$ methanol and $40 \%$ deionized water, was set in isocratic mode with a flow rate of $0.7 \mathrm{~mL} / \mathrm{min}$. The detection wavelength was set at 229 $\mathrm{nm}$. The injection volume was $20.0 \mu \mathrm{L}$ and the total run time was fixed at $10 \mathrm{~min}$. Data acquisition and analysis were performed using Agilent Chemstation Software coupled to the computer. Five mg of SEDS co-precipitates was dissolved in $10 \mathrm{~mL}$ methanol, diluted with mobile phase, filtered using a $0.22 \mu \mathrm{m}$ syringe filter and injected onto the HPLC system for determination. Andrographolide content was quantified by comparison with an andrographolide standard calibration curve. Ten $\mathrm{mg}$ of andrographolide standard was dissolved in $10 \mathrm{~mL}$ of methanol, then diluted to a series of concentrations $(\mathrm{mg} / \mathrm{mL}) 0.01$, $0.05,0.10,0.15,0.20$, and 0.25 . Andrographolide content of $A$. paniculata extract was determined for comparison. Each determination was conducted in duplicate.

\section{Storage stability study of andrographolide from SEDS co-precipitates}

The storage stability study of SEDS co-precipitates was conducted at $5 \pm 2,30 \pm 2$, and $45 \pm 2{ }^{\circ} \mathrm{C}$ at $75 \pm 5 \%$ relative humidity (RH) according to Plubrukarn et al. (2006) with slight modifications. Temperature higher than $45{ }^{\circ} \mathrm{C}$ was not administered due to poor andrographolide stability in those elevatedtemperature systems as reported (Lomlim et al., 2003; Plubrukarn et al., 2006; Wongkittipong et al., 2004). Since stability study of andrographolide in dried $A$. paniculata plants at ambient conditions conducted by Pholphana et al. (2004) showed only a decrement of the content of andrographolide during the first three months in a 15-month study period, our study period was adjusted to be less than three months. SEDS coprecipitates were initially filled into separate petri dishes, then placed into closed desiccators containing saturated $\mathrm{NaCl}$ solution in order to furnish an atmosphere of $75 \pm 5 \% \mathrm{RH}$ under darkness at different temperatures. The andrographolide content of SEDS co-precipitates was determined before the storage period and consecutively after 21,49 , and 64 days of storage under different conditions as stated. Samples were randomly collected in duplicate during the sampling period for determination of the percentage of andrographolide content (\%) using HPLC. The order of the andrographolide degradation was determined by the representation that gave a linear plot over the time course of reaction (Schmitz, 2017). The determination of the order of reaction started from zeroth, followed by first and second order. If a plot of [A] versus $t$ is linear, then it is a zeroth-order reaction. If a plot of $\ln$ [A] versus $t$ is linear, then it is a first-order with the slope of plot as the rate constant. If a plot of $1 /[\mathrm{A}]$ versus $t$ is linear, then it is a second order reaction. For a second-order reaction, the plot of $\ln [\mathrm{A}]$ versus $t$ is not linear (Schmitz, 2017). Shelf life $\left(t_{90 \%}\right)$ and half-life $\left(\mathrm{t}_{1 / 2}\right)$ of SEDS co-precipitates were calculated using equations (1) to (6) as follow:

Zeroth-order: $[\mathrm{A}]=[\mathrm{A}]_{\mathrm{o}}-\mathrm{kt}$

$$
\begin{aligned}
& \mathrm{t}_{90 \%}=0.1[\mathrm{~A}]_{0} / \mathrm{k} \\
& \mathrm{t}_{1 / 2}=[\mathrm{A}]_{0} / 2 \mathrm{k}
\end{aligned}
$$

First-order: $\ln [\mathrm{A}]=\ln [\mathrm{A}]_{0}-\mathrm{kt}$

$\mathrm{t}_{90 \%}=-\ln 0.9 / \mathrm{k}$

$\mathrm{t}_{1 / 2}=\ln 2 / \mathrm{k}$ 


$$
\begin{aligned}
& \mathrm{t}_{90 \%}=0.11[\mathrm{~A}] / \mathrm{k}[\mathrm{A}]_{。} \\
& \mathrm{t}_{1 / 2}=1 / \mathrm{k}[\mathrm{A}]_{。}
\end{aligned}
$$$$
\text { Second order: } 1 /[\mathrm{A}]=1 /[\mathrm{A}]_{\mathrm{o}}+\mathrm{kt}
$$

where $[\mathrm{A}]_{\mathrm{o}}$ is the initial content of andrographolide, $[\mathrm{A}]$ is the content of andrographolide at time $\mathrm{t}$, and $\mathrm{k}$ is the rate constant.

\section{Stability study of andrographolide from SEDS co- precipitates after addition into model food systems}

Three different RTD beverages, namely drinking water, orange drink, and soybean milk, were selected as model food systems for the stability study of andrographolide after SEDS co-precipitates were respectively added into the food model systems. Thirty $\mathrm{mg}$ of SEDS co-precipitates were added into $10 \mathrm{~mL}$ of RTD beverages, then stirred, sealed, followed by storage in the dark under $5^{\circ} \mathrm{C}$ for three days only since the intended application of the SEDS co-precipitates is for instant addition into RTD beverages for enrichment purposes before consumption. The andrographolide content was determined before the storage period and consecutively after 1,2 , and 3 days of storage. Samples were randomly collected in duplicate during the sampling period for the determination of the percentage of andrographolide content (\%) using HPLC. The $\mathrm{pH}$ of RTD beverage mixtures was monitored and recorded before and along the storage period to check on the compatibility of added SEDS co-precipitates with different RTD beverages to help as well in defining the extent of the study period.

\section{Toxicity of SEDS co-precipitates}

\section{Solvent residue test}

Headspace GC-MS analysis with reference to Jacq et al. (2008) was conducted to detect the acetone residue in SEDS co-precipitates. Prior to GC-MS analysis, $20 \mathrm{mg}$ of SEDS co-precipitates were weighed into a $20 \mathrm{~mL}$ headspace vial, followed by addition of $10 \mathrm{~mL}$ distilled water. The condition of the Agilent G1888 static headspace sampler was set as follows: vial equilibrium time of $10 \mathrm{~min}$, oven temperature at $80{ }^{\circ} \mathrm{C}$, loop temperature at $120{ }^{\circ} \mathrm{C}$, transfer line temperature $120{ }^{\circ} \mathrm{C}$. Samples were then injected into a DB-624 GC column packed with $94 \%$ dimethyl polysiloxane and $6 \%$ cyanopropyl phenyl ( $20 \mathrm{~m}$ x 0.18 $\mathrm{mm}$ i.d. x $1 \mu \mathrm{m}$ film thickness, Agilent J \& W 1211324, USA) housed in an Agilent 7890A GC/5975C MSD system comprising a gas chromatograph (GC) coupled with a mass selective detector (MSD). Helium was used as carrier gas at a flow of $1 \mathrm{~mL} / \mathrm{min}$. The stepped oven temperature program was set as follows: held at $40{ }^{\circ} \mathrm{C}$ for $3 \mathrm{~min}$, then from 40 to $120{ }^{\circ} \mathrm{C}$ at the rate of $30^{\circ} \mathrm{C} / \mathrm{min}$, and from 120 to $220^{\circ} \mathrm{C}$ at the rate of $40{ }^{\circ} \mathrm{C} / \mathrm{min}$. The injector was set at $250^{\circ} \mathrm{C}$ and injection mode with split ratio of 50:1 was employed. Solvent delay was $1 \mathrm{~min}$. The total run time was $8 \mathrm{~min}$. The following settings were applied in the operation of MSD: transfer line temperature at $280{ }^{\circ} \mathrm{C}$, ion source temperature at $230{ }^{\circ} \mathrm{C}$, quadrupole temperature at 150 ${ }^{\circ} \mathrm{C}$, mass scan from 30 to $300(\mathrm{~m} / \mathrm{z})$. The presence of acetone in co-precipitates was identified and confirmed by comparing the retention time with that of acetone standard and the quantitation was conducted using selected ion monitoring (SIM) mode. The acetone standard calibration curve was plotted at the following concentrations: $0.1,3.14,6.28,9.42$, and $12.56 \mathrm{ppm}$.

\section{Brine shrimp bioassay}

Sample preparation was conducted as described in Meyer et al. (1982). Fifty mg of extract or sample were dissolved into $5 \mathrm{~mL}$ of methanol to form Solution A. Solution B was prepared by diluting $0.5 \mathrm{~mL}$ of Solution A to $10 \mathrm{~mL}$ with methanol. Amounts of 100 $\mu \mathrm{L}$ Solution B, $50 \mu \mathrm{L}$ Solution A, and $500 \mu \mathrm{L}$ Solution A were transferred to a small disc of filter paper to form 10,100 , and $1000 \mu \mathrm{g} / \mathrm{mL}$ samples, respectively, in the final $5 \mathrm{~mL}$ of artificial sea water. Control discs were prepared from the lowest amount $(50 \mu \mathrm{L})$ to the highest amount $(500 \mu \mathrm{L})$ of methanol without presence of extract or sample. The discs of filter papers were dried in air and placed into $5 \mathrm{~mL}$ vials. Ten replicates were prepared for each different dose level. To hatch the brine shrimp, first a clean hatching container was used. An open air tube was installed in the tip to give aeration while a light source was installed at the top of the container. The container was filled with fresh tap water followed by addition of brine shrimp eggs in sea salt premix. Continuous aeration was important to keep cysts in suspension. Hatching was completed after 24 $\mathrm{h}$ incubation at room temperature $\left(29^{\circ} \mathrm{C}\right)$. The aeration and light source were removed from the container to allow the empty cyst shells to float while the live Artemia nauplii settle to the bottom of container. The nauplii were collected, rinsed with artificial sea water (prepared using $35 \mathrm{~g} \mathrm{NaCl}$ in $1 \mathrm{~L}$ of tap water) and transferred into a container of fresh artificial sea water. For the bioassay, ten nauplii were transferred into each vial containing the disc of sample using a disposable pipette, and artificial sea water was added to make 5 $\mathrm{mL}$. The nauplii could be measured macroscopically in the stem of pipette against a lighted background. A drop of yeast suspension (prepared using $3 \mathrm{mg}$ in 5 $\mathrm{mL}$ artificial sea water) was added into the vial as food for the nauplii. A light source was provided along the incubation period for $24 \mathrm{~h}$. After $24 \mathrm{~h}$, the number of survivors in each vial was measured.

The percent of death at each dose level and control were determined. In cases where control death 
occurred, the data were corrected using Abbott's formula (7):

$\%$ death $=([$ test - control $] /$ control $) \times 100 \%$

Lethal concentration $\left(\mathrm{LC}_{50}\right)$ and $95 \%$ confidence interval were determined from the $24 \mathrm{~h}$ count through the probit analysis method using Minitab 16 software (Minitab Inc., State College, PA, USA).

\section{RESULTS AND DISCUSSION}

\section{Physical and chemical properties of SEDS co- precipitates}

The SEDS process successfully allowed the transformation of the sticky paste of A. paniculata extract into SEDS co-precipitates after being formulated with Eudragit L100-55. During the SEDS process, sc- $\mathrm{CO}_{2}$ acted as anti-solvent to extract out acetone that was used to dissolve both $A$. paniculata extract and Eudragit L100-55, leaving the formation of co-precipitates that were practically solvent-free in the precipitation chamber. As shown in Figure 2, the SEDS co-precipitates produced were visually good in terms of colour retainment and particulate formation when compared to the initial dark blackish green $A$. paniculata paste.

SEM photographs of both SEDS precipitated Eudragit L100-55 powder and SEDS co-precipitates are shown in Figure 3.

From the XRD plot as shown in Figure 4, it could be seen that the SEDS co-precipitates had lower crystallinity as compared to SEDS precipitated $A$. paniculata extract powder. SEDS precipitated $A$. paniculata extract powder was obtained at similar SEDS co-precipitation conditions, but with the absence of Eudragit L100-55 in the formulation. In addition, the SEDS co-precipitation process allowed

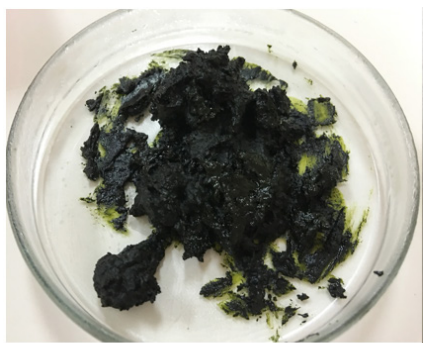

(a)

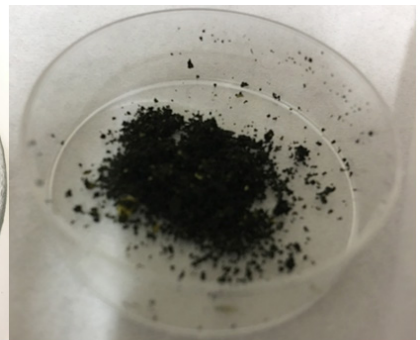

(b)
Figure 2. Dark blackish green A. paniculata paste obtained from maceration using acetone as extraction solvent (a), SEDS co-precipitates 6:25 (Eudragit L100-55:A. paniculata) obtained at 150 bar, $40{ }^{\circ} \mathrm{C}, 15$ $\mathrm{L} / \mathrm{min}$ of $\mathrm{CO}_{2}$ flow rate, $0.5 \mathrm{~mL} / \mathrm{min}$ of liquid feed flow rate, and acetone used as feed solvent (b).

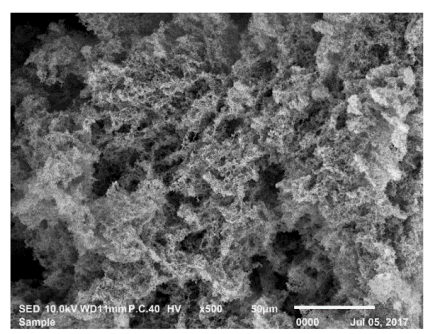

(a)

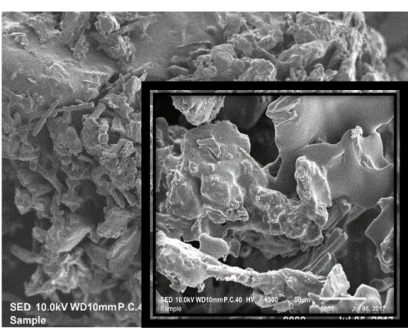

(b)
(Source: Reprinted from Journal of Drug Delivery Science and Technology, Vol. 50, Lee, S.Y., Abdullah, L.C., Abdul Rahman, R., Abas, F., Chong, G.H., Role of polymers as crystal growth inhibitors in coprecipitation via solution-enhanced dispersion by supercritical fluids (SEDS) to improve andrographolide dissolution from standardized Andrographis paniculata extract, 145-154, Copyright 2019, with permission from Elsevier.)

Figure 3. Scanning Electron Microscopy (SEM) photographs of Solution Enhanced Dispersion by Supercritical Fluids (SEDS) precipitated Eudragit L100-55 (a), SEDS co-precipitates 6:25 (Eudragit L100-55:A. paniculata) obtained at $150 \mathrm{bar}, 40{ }^{\circ} \mathrm{C}, 15$ $\mathrm{L} / \mathrm{min}$ of $\mathrm{CO}_{2}$ flow rate, $0.5 \mathrm{~mL} / \mathrm{min}$ of liquid feed flow rate, and acetone used as feed solvent (b).
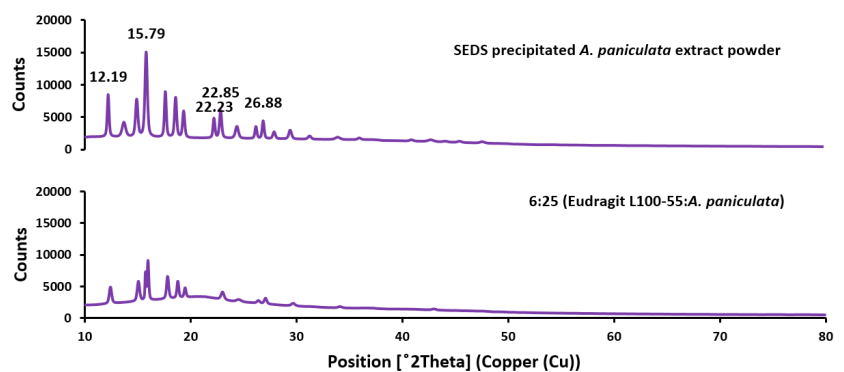

(Source: Reprinted from Journal of Drug Delivery Science and Technology, Vol. 50, Lee, S.Y., Abdullah, L.C., Abdul Rahman, R., Abas, F., Chong, G.H., Role of polymers as crystal growth inhibitors in coprecipitation via solution-enhanced dispersion by supercritical fluids (SEDS) to improve andrographolide dissolution from standardized Andrographis paniculata extract, 145-154, Copyright 2019, with permission from Elsevier.)

Figure 4. X-Ray Diffraction (XRD) pattern of SEDS precipitated $A$. paniculata extract powder and SEDS co-precipitates 6:25 (Eudragit L100-55:A. paniculata) obtained at $150 \mathrm{bar}, 40^{\circ} \mathrm{C}, 15 \mathrm{~L} / \mathrm{min}$ of $\mathrm{CO}_{2}$ flow rate, $0.5 \mathrm{~mL} / \mathrm{min}$ of liquid feed flow rate, and acetone as feed solvent.

the co-precipitates formulated to contain $20.4 \% \mathrm{w} / \mathrm{w}$ andrographolide, while the initial andrographolide content of $A$. paniculata extract was $16 \% \mathrm{w} / \mathrm{w}$. The increase of content of andrographolide in SEDS coprecipitates could be due to extraction of undesired compounds from the crude extract during SEDS co-precipitation, which resulted in an increase of concentration of andrographolide in SEDS coprecipitates compared to the starting material, in this case the crude extract. Similar findings of a concentration effect by the supercritical anti-solvent method, concentrating the active compound from $20 \% \mathrm{w} / \mathrm{w}$ in the crude extract up to $36 \% \mathrm{w} / \mathrm{w}$ in precipitates, has also been reported (Baldino et al., 2018). 


\section{Storage stability study of andrographolide from co- precipitates}

The degradation of andrographolide from the SEDS co-precipitates during the sampling periods up to 64 days did not fit into zeroth-order kinetics as the plot of percentage of andrographolide versus time $t$ showed curvature rather than being linear. Instead, it fitted first-order kinetics where the linearity was best met when $\ln [\%$ of andrographolide] was plotted against time $\mathrm{t}$ for different storage temperatures as shown in Figure 5.

First-order kinetics of degradation of andrographolide were also reported by Wongkittipong et al. (2004). First-order degradation simply means that the degradation of andrographolide is concentrationdependent, therefore the amount of andrographolide degrading per unit of time is not constant for the coprecipitates. Most drugs tend to degrade by either zeroth- or first-order kinetics (Brooks et al., 2017). However, second-order kinetics of degradation of andrographolide was also reported for herb and solid dispersion in PVP-K30 (Lomlim et al., 2003; Plubrukarn et al., 2006). Second-order degradation means the degradation rate depends on either concentration of two same or two different reactants. Therefore, the difference in terms of degradation kinetics reported could be due to the different matrix or formulation of andrographolide being studied.

The first-order rate equation, rate constant $(\mathrm{k})$, coefficient of determination $\left(\mathrm{R}^{2}\right)$ of andrographolide degradation, shelf-life $\left(\mathrm{t}_{90 \%}\right)$, and half-life $\left(\mathrm{t}_{1 / 2}\right)$

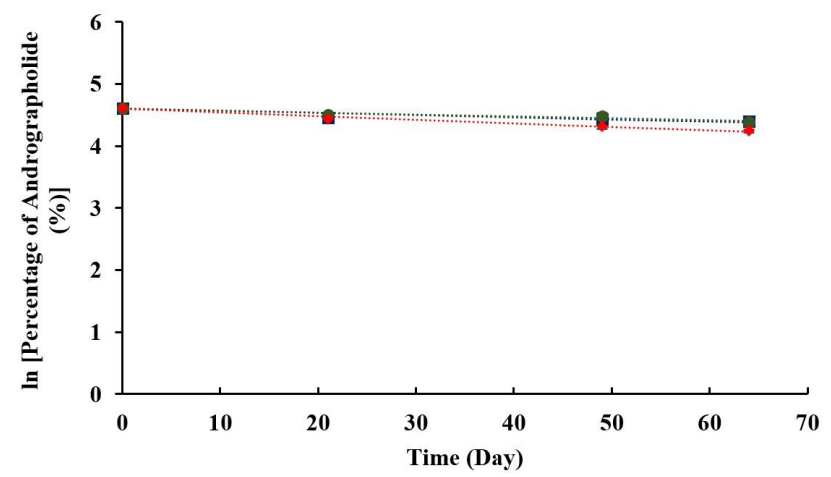

Figure 5. First-order plots of degradation of andrographolide from SEDS co-precipitates at $5^{\circ} \mathrm{C}(\mathbf{\square})$, calculated from the model for $5{ }^{\circ} \mathrm{C}(\cdots)$, at $30^{\circ} \mathrm{C}(\bullet)$, calculated from the model for $30^{\circ} \mathrm{C}(\cdots)$, at $45^{\circ} \mathrm{C}(\diamond)$, calculated from the model for $45^{\circ} \mathrm{C}(\cdots)$. of andrographolide of SEDS co-precipitates at different storage temperatures are shown in Table 1. It could be seen that the degradation rate constant of andrographolide from SEDS co-precipitates was found to be the highest at the highest storage temperature. Similar findings have been reported where the increment of temperature resulted in a greater degradation rate constant of andrographolide [rate constant $=0.0085 \mathrm{~min}^{-1}\left(86{ }^{\circ} \mathrm{C}\right), 0.0229 \mathrm{~min}^{-1}$ $\left(92{ }^{\circ} \mathrm{C}\right)$, and $\left.0.048 \mathrm{~min}^{-1}\left(97^{\circ} \mathrm{C}\right)\right]$, at higher temperature (Wongkittipong et al., 2004).

In terms of shelf life and half-life, it could be seen from Table 1 that the increment of storage temperature from 5 to $45{ }^{\circ} \mathrm{C}$ resulted in a decrement of both shelf life and half-life approximately up to 1.6-fold for SEDS co-precipitates. Because almost the same shelf life and half-life of andrographolide of SEDS co-precipitates are predicted at 5 and $30^{\circ} \mathrm{C}$, the most probable storage condition suggested would be the ambient condition to be practical and economic in future applications. Similarly, an ambient storage condition for andrographolide from herb has also been suggested (Ibrahim and Chong, 2008).

Stability study of andrographolide from SEDS coprecipitates after addition into model food systems

Along the stability period, the $\mathrm{pH}$ of each beverage mixture was found to be constant as shown in Figure 6 . This showed compatibility of SEDS co-precipitates with different RTD beverages.

Figure 7 shows the degradation of andrographolide from SEDS co-precipitates after its addition into three different RTD beverages from day 0 to day 3 .

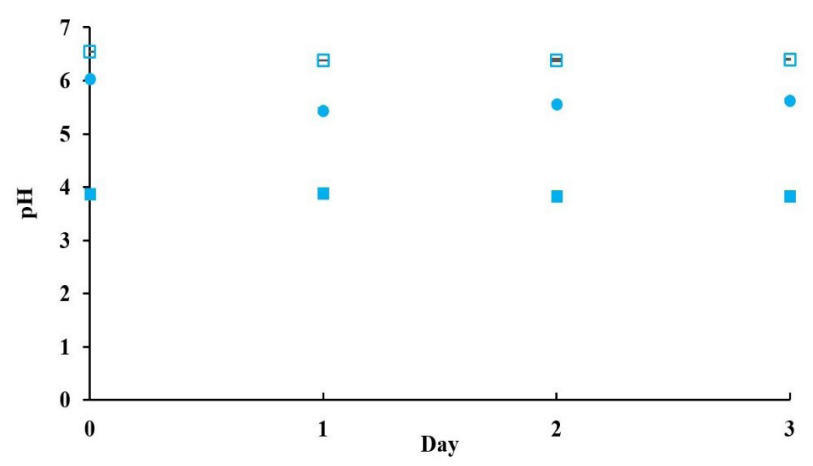

Figure 6. $\mathrm{pH}$ of beverage mixtures after addition of SEDS co-precipitates into drinking water $(\bullet)$, soybean milk ( $\square)$, orange drink ( $\square$ ).

Table 1. First-order rate equation, rate constant $(\mathrm{k})$, coefficient of determination $\left(\mathrm{R}^{2}\right)$ of andrographolide degradation, shelf-life $\left(\mathrm{t}_{90 \%}\right)$, and half-life $\left(\mathrm{t}_{1 / 2}\right)$ of andrographolide from SEDS co-precipitates at different storage temperatures.

\begin{tabular}{|c|c|c|c|c|}
\hline \multirow{2}{*}{ Temperature $\left({ }^{\circ} \mathrm{C}\right)$} & \multicolumn{4}{|c|}{ SEDS co-precipitated $A$. paniculata with Eudragit L100-55 } \\
\hline & Rate equation & $k\left(d^{-1}\right)$ & t90\% (year) & $\mathbf{t}_{1 / 2}($ year $)$ \\
\hline 5 & $\ln A=-0.0035 t+4.6052 \quad R^{2}=0.8372$ & 0.0035 & 0.08 & 0.54 \\
\hline 30 & $\ln \mathrm{A}=-0.0032 \mathrm{t}+4.6052 \mathrm{R}^{2}=0.8998$ & 0.0032 & 0.09 & 0.59 \\
\hline 45 & $\ln A=-0.0059 t+4.6052 R^{2}=0.9720$ & 0.0059 & 0.05 & 0.32 \\
\hline
\end{tabular}


Table 2. Brine shrimp bioassay results.

\begin{tabular}{|c|c|c|c|c|c|}
\hline \multirow[t]{2}{*}{ Samples } & \multicolumn{3}{|c|}{$\begin{array}{l}\text { Percent deaths of brine shrimp } \\
\text { after } 24 \text { h exposure }(\mu \mathrm{g} / \mathrm{mL})\end{array}$} & \multirow{2}{*}{$\begin{array}{c}\mathrm{LC}_{50} \\
(\mu \mathrm{g} / \mathrm{mL})\end{array}$} & \multirow{2}{*}{$\begin{array}{l}95 \% \text { CI } \\
(\mu \mathrm{g} / \mathrm{mL})\end{array}$} \\
\hline & 10 & 100 & 1000 & & \\
\hline Fresh $A$. paniculata extract & 11 & 40 & 92 & $150.45 \pm 23.01$ & $108.65-200.21$ \\
\hline SEDS Co-precipitates & 21 & 67 & 92 & $46.46 \pm 8.31$ & $32.01-65.70$ \\
\hline
\end{tabular}

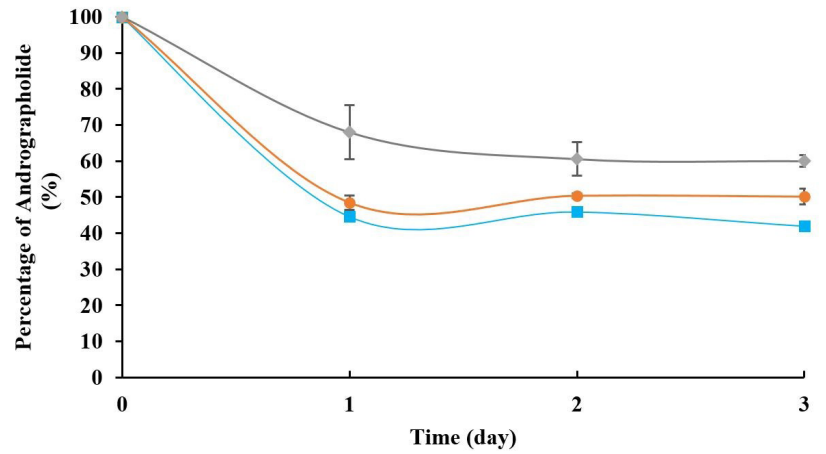

Figure 7. Degradation of andrographolide from SEDS co-precipitates in drinking water $(\bullet)$, orange drink $(\bullet)$, and soybean milk ( $\bullet$.

Overall, the same trend of andrographolide degradation was observed from SEDS co-precipitates in all three different $\mathrm{pH}$ RTD beverages. After addition of SEDS co-precipitates into the RTD beverages for a day at $5{ }^{\circ} \mathrm{C}$, andrographolide had been degraded by about $40-70 \%$ of its initial concentration and the concentration of andrographolide remained in the consecutive days. Andrographolide from SEDS coprecipitates was found to be the least stable in drinking water compared to soybean milk and orange drink. This could be due to higher dissolved oxygen content in drinking water while the presence of different food components in soybean milk and orange drinks might confer a protective effect towards andrographolide. Similar findings on anti-oxidative effect of different food components of skimmed milk and orange drink on astaxanthin compared to water have also been reported (Anarjan and Tan, 2013).

\section{Toxicity study}

From the headspace GC-MS analysis, the estimated acetone content in the SEDS co-precipitates was found to be less than $0.1 \mathrm{ppm}$, which met the requirement set with permitted daily exposure (PDE) of $50 \mathrm{mg} /$ day or $5000 \mathrm{ppm}$ or higher provided that the amount is realistic in relation to manufacturing capacity according to the International Conference for Harmonisation of Technical Requirements for Registration of Pharmaceuticals for Human Use (ICH) Guideline Q3C(R6) on Impurities: Guideline for Residual Solvents (ICH, 2016). Throughout the studies reported on compound treatment by the supercritical anti-solvent process with usage of Class III solvents such as ethanol, acetone, and DMSO, sc- $\mathrm{CO}_{2}$ acting as anti-solvent was able to extract out the solvent, resulting in an amount of detected solvent residue much lower than the International Conference on Harmonisation (ICH) requirements (Miao et al., 2018; Zhao et al., 2010). This shows the efficiency of the anti-solvent in the SEDS process in removing solvent from the feed during the precipitation and washing process in the precipitation chamber.

From Table 2, it could be seen that all samples tested in the brine shrimp bioassay, including fresh $A$. paniculata extract and SEDS co-precipitates, showed $\mathrm{LC}_{50}$ less than $1000 \mu \mathrm{g} / \mathrm{mL}$. According to Meyer et al. (1982), compounds with $\mathrm{LC}_{50}$ less than $1000 \mu \mathrm{g} / \mathrm{mL}$ are considered bioactive in the brine shrimp bioassay.

Overall, the toxicity of both fresh $A$. paniculata extract and SEDS co-precipitates towards brine shrimp were concentration-dependent. The $\mathrm{LC}_{50}$ value obtained for fresh $A$. paniculata extract was close to the one reported for whole $A$. paniculata extract, which was in the range of 100 to $300 \mu \mathrm{g} / \mathrm{mL}$ (Mamatha, 2014). For a $\mathrm{LC}_{50}$ value in the range of 100 to $500 \mu \mathrm{g} / \mathrm{mL}$, samples are considered to be non-toxic (Moshi et al., 2010). However, the SEDS co-precipitates with $\mathrm{LC}_{50}$ value between 30 and $100 \mu \mathrm{g} / \mathrm{mL}$ could be categorized as mildly toxic. While Eudragit L100-55 had been shown to be a safe drug carrier that displayed insignificant cytotoxicity in a study conducted by Hao et al. (2013), the increased $\mathrm{LC}_{50}$ of SEDS co-precipitates could be an indicative of its higher cytotoxic potential after SEDS co-precipitation. SEDS co-precipitation improved the dissolution of andrographolide of our formulated A. paniculata extract as determined in our previous study (data not shown) and could be making it more bioactive towards newly hatched brine shrimp.

\section{CONCLUSION}

The lower stability of andrographolide from SEDS co-precipitates in liquid food systems could be due to the presence of water as plasticizing agent that increased its molecular mobility and degradation. In view of the lower andrographolide stability in liquid food systems, the SEDS co-precipitates formulated are suggested to be more suitable to be dusted on dry food systems as toppings. For applications of SEDS co-precipitates in liquid food systems such as RTD beverages, instant addition followed by consumption is suggested to be more suitable. From the negligible residual solvent content of SEDS co-precipitates, the SEDS process conditions applied are capable of 
removing most of the solvent during co-precipitation. Therefore, the higher cytotoxic potential of the SEDS co-precipitates may not be due to its residual solvent but rather the presence of potent cytotoxic components that warrant further investigation in suitable application dosages before incorporation into food.

\section{ACKNOWLEDGEMENTS}

We gratefully acknowledge Jebsen \& Jessen Ingredients for the free supply of Eudragit L100-55 polymer for our study. This work was supported by the Fundamental Research Grant Scheme of Ministry of Education Malaysia (Project code: 03-01-15-1732FR).

\section{NOMENCLATURE}

$\begin{array}{ll}\dot{A} & \begin{array}{l}\text { Angstrom as measurement of thin film } \\ \text { thickness }\end{array} \\ \text { LC }_{50} \quad \text { Lethal concentration }\end{array}$

\section{REFERENCES}

Ameri, M., Maa, Y. F., Spray Drying of Biopharmaceuticals: Stability and Process Considerations, DryingTechnol., 24,763-768(2006). https://doi.org/10.1080/03602550600685275

Anarjan, N., Tan, C.P., Chemical Stability of Astaxanthin Nanodispersions in Orange Juice and Skimmed Milk as Model Food Systems, Food Chem., 139, 527-531 (2013). https://doi. org/10.1016/j.foodchem.2013.01.012

Bakowska-Barczak, A. M.; Kolodziejczyk, P. P., Black Currant Polyphenols: Their Storage Stability and Microencapsulation, Ind. Crops Prod., 34, 1301-1309 (2011). https://doi.org/10.1016/j. indcrop.2010.10.002

Baldino, L., Porta, G. D., Osseo, L. S., Reverchon, E., Adami, R., Concentrated Oleuropein Powder from Olive Leaves Using Alcoholic Extraction and Supercritical $\mathrm{Co}_{2}$ Assisted Extraction, J. Supercrit. Fluids, 133, 65-69 (2018). https://doi.org/10.1016/j. supflu.2017.09.026

Bhandari, B. R., Howes, T., Implication of Glass Transition for the Drying and Stability of Dried Foods, J. Food Eng., 40, $71-79$ (1999). https://doi. org/10.1016/S0260-8774(99)00039-4

Bott, R. F., Labuza, T. P., Oliveira, W. P., Stability Testing of Spray- and Spouted Bed-Dried Extracts of Passiflora alata, Drying Technol., 28, 12551265 (2010). https://doi.org/10.1080/07373937.20 10.482718

Brooks, A. D., Sanoski, C., Hajjar, E. R., Overholser, B. R., Naplex 2017 Strategies, Practice \& Review with 2 Practice Tests: Online + Book, Kaplan Publishing, New York (2017). de Oliveira, W. P., de Freitas, L. A. P., Freire, J. T., Drying of Pharmaceutical Products, Transport Phenomena in Particulate Systems, Freire, J. T., Silveira, A. M., Ferreira, M. C., eds., Bentham Science, pp. 148-171 (2012). https://doi.org/10.21 74/978160805227111201010148

Hao, S., Wang, B., Wang, Y., Zhu, L., Wang, B., Guo, T., Preparation of Eudragit L 100-55 Enteric Nanoparticles by a Novel Emulsion Diffusion Method, Colloids Surf. B Biointerfaces, 108, 127-133 (2013). https://doi.org/10.1016/j. colsurfb.2013.02.036

Ibrahim, M. N., Chong, G. H., Stability of Andrographolide in Andrographis paniculata under Selected Storage Conditions, Int. J. Eng. Technol., 5, 69-73 (2008).

ICH, Ich Guideline Q3c(R6) on Impurities: Guideline for Residual Solvents, International Conference for Harmonisation of Technical Requirements for Registration of Pharmaceuticals for Human Use (ICH), Switzerland (2016).

Jacq, K., David, F., Sandra, P., Klee, M. S., A Generic Method for the Analysis of Residual Solvents in Pharmaceuticals Using Static Headspace-Gc-Fid/ Ms, Agilent Technologies, Inc., United States, pp. 1-12 (2008).

Jiménez-Aguilar, D. M., Ortega-Regules, A. E., Lozada-Ramírez, J. D., Pérez-Pérez, M. C. I., Vernon-Carter, E. J., Welti-Chanes, J., Color and Chemical Stability of Spray-Dried Blueberry Extract Using Mesquite Gum as Wall Material, J. Food Compost. Anal., 24, 889-894 (2011). https:// doi.org/10.1016/j.jfca.2011.04.012

King, J. W., Modern Supercritical Fluid Technology for Food Applications, Annu. Rev. Food Sci. Technol., 5, 215-238 (2014). https://doi.org/10.1146/ annurev-food-030713-092447

Lee, S. Y., Abdullah, L. C., Abdul Rahman, R., Abas, F., Tan, W. K., Chong, G. H., Solution Enhanced Dispersion by Supercritical Fluids (Seds): An Approach in Particle Engineering to Modify Aqueous Solubility of Andrographolide from Andrographis paniculata Extract, Chem. Eng. Res. Des., 138, 176-189 (2018). https://doi. org/10.1016/j.cherd.2018.08.029

Lee, S. Y., Abdullah, L. C., Abdul Rahman, R., Abas, F., Chong, G. H., Role of Polymers as Crystal Growth Inhibitors in Coprecipitation via SolutionEnhanced Dispersion by Supercritical Fluids (SEDS) to Improve Andrographolide Dissolution from Standardized Andrographis paniculata Extract, J. Drug Deliv Sci Technol., 50, 145-154 (2019). https://doi.org/10.1016/j.jddst.2019.01.026

Lomlim, L., Jirayupong, N., Plubrukarn, A., Heat-Accelerated Degradation of Solid-State Andrographolide, Chem. Pharm. Bull. (Tokyo), 51, 24-26 (2003). https://doi.org/10.1248/cpb.51.24 
Mamatha, A., Brine Shrimp Lethality Test of Andrographis paniculata., Res. J. Pharm. Technol., 7, 743-745 (2014).

Meyer, B. N., Ferrigni, N. R., Putnam, J. E., Jacobsen, L. B., Nichols, D. E., McLaughlin, J. L., Brine Shrimp: A Convenient General Bioassay for Active Plant Constituents, Planta Med., 45, 31-34 (1982). https://doi.org/10.1055/s-2007-971236

Miao, H., Chen, Z., Xu, W., Wang, W., Song, Y., Wang, Z., Preparation and Characterization of Naringenin Microparticles Via a Supercritical Anti-Solvent Process, J. Supercrit. Fluids, 131, 19-25 (2018). https://doi.org/10.1016/j.supflu.2017.08.013

Moshi, M. J., Innocent, E., Magadula, J. J., Otieno, D. F., Weisheit, A., Mbabazi, P. K., Nondo, R. S., Brine Shrimp Toxicity of Some Plants Used as Traditional Medicines in Kagera Region, North Western Tanzania, Tanzan. J. Health Res., 12, 63-67 (2010). https://doi.org/10.4314/thrb.v12i1.56287

Oliveira, W. P., Souza, C. R. F, Kurozawa, L. E., Park, K. J., Spray Drying of Food and Herbal Products, Spray Drying Technology, Woo, M. W., Mujumdar, A. S., Daud, W. R. W., eds., Singapore, pp. 113-156 (2010).

Panossian, A., Hovhannisyan, A., Mamikonyan, G., Abrahamian, H., Hambardzumyan, E., Gabrielian, E., Goukasova, G., Wikman, G., Wagner, H., Pharmacokinetic and Oral Bioavailability of Andrographolide from Andrographis paniculata Fixed Combination Kan Jang in Rats and Human, Phytomedicine, 7, 351-364 (2000). https://doi. org/10.1016/S0944-7113(00)80054-9

Pholphana, N., Rangkadilok, N., Thongnest, S., Ruchirawat, S., Ruchirawat, M., Satayavivad, J., Determination and Variation of Three Active Diterpenoids in Andrographis paniculata (Burm.F.) Nees, Phytochem. Anal., 15, 365-371 (2004). https://doi.org/10.1002/pca.789

Plubrukarn, A., Pinsuwan, S., Ingkatawornwong, S., Supavita, T., Stability of Andrographolide in Powdered Andrographis Herb under Accelerated Conditions, Planta Med., 72, 954-956 (2006). https://doi.org/10.1055/s-2006-946696
Rocha, G. A., Fávaro-Trindade, C. S., Grosso, C. R. F., Microencapsulation of Lycopene by Spray Drying: Characterization, Stability and Application of Microcapsules, Food Bioprod. Process., 90, 37-42 (2012). https://doi.org/10.1016/j.fbp.2011.01.001

Schmitz, K. S., Reaction Rates and Mechanisms, Physical Chemistry: Concepts and Theory, Schmitz, K. S., ed., Chapter 15, Elsevier, pp. 695760 (2017). https://doi.org/10.1016/B978-0-12800514-9.00015-8

Sule, A., Ahmed, Q. U., Samah, O. A., Omar, M. N., Hassan, N. M., Kamal, L. Z. M., Yarmo, M. A., Bioassay Guided Isolation of Antibacterial Compounds from Andrographis paniculata, Am. J. Appl. Sci., 8, 525-534 (2011). https://doi. org/10.3844/ajassp.2011.525.534

Wachtel-Galor, S., Benzie, I. F. F., Herbal Medicine: An Introduction to Its History, Usage, Regulation, Current Trends, and Research Needs, Herbal Medicine: Biomolecular and Clinical Aspects, Benzie, I. F. F., Wachtel-Galor, S., eds., CRC Press, Boca Raton (2011).

Wongkittipong, R., Prat, L., Damronglerd, S., Gourdon, C., Solid-Liquid Extraction of Andrographolide from Plants-Experimental Study, Kinetic Reaction and Model, Sep. Purif. Technol., 40, 147-154(2004). https://doi.org/10.1016/j.seppur.2004.02.002

Yatsu, F. K. J., Borghetti, G. S., Bassani, V. L., Technological Characterization and Stability of Ilex Paraguariensis St. Hil. Aquifoliaceae (Mate) Spray-Dried Powder, J. Med. Food, 14, 413-419 (2011). https://doi.org/10.1089/jmf.2010.0044

Zhang, D., Lin, J., Zhang, F., Han, X., Han, L., Yang, M., Zou, W., Preparation and Evaluation of Andrographolide Solid Dispersion Vectored by Silicon Dioxide, Pharmacogn. Mag., 12, 245-252 (2016). https://doi.org/10.4103/0973-1296.182156

Zhao, X., Zu, Y., Li, Q., Wang, M., Zu, B., Zhang, X., Jiang, R., Zu, C., Preparation and Characterization of Camptothecin Powder Micronized by a Supercritical Antisolvent (Sas) Process, J. Supercrit. Fluids, 51, 412-419 (2010). https://doi. org/10.1016/j.supflu.2009.10.004 